\title{
Carbapenem Resistance Of Pseudomonas Aeruginosa: A Review
}

\author{
Shaista Bakhat, Yasmeen Taj, Faisal Hanif \\ - - - - - - - - - - - - - - - - - - - --------------
}

ABSTRACT

Carbapenem resistance towards the gram negative microorganisms especially Pseudomonas aeruginosa is alarming and on-going public health problem all over the world. It may be intrinsic or acquired through transcription of genes among microorganisms. These genes are spreading rapidly and are responsible for serious out-breaks. So selection of antibiotics is limited to treat these resistant cases. Resistant genes are commonly extended in Europe, Asia (Turkey, India, China, Pakistan and so on) and South America. In Pakistan carbapenem resistance in Pseudomonas aeruginosa isolates is increasing among hospitalized patients. It shows a progressive trend in multidrug resistance (even towards last resort drug carbapenem). In this article, we offer an in-depth review of carbapenem resistant Pseudomonas aeruginosa. This will facilitate the readers to take effective measures in order to control infection and appropriate use of antibiotics.

Keywords: appropriate antibiotics, Carbapenem resistant, transcription of genes.

\section{INTRODUCTION:}

Pseudomonas aeruginosa is opportunistic and non fastidious pathogen. This bacterium is a threat in particular to those hospitalized patients who are dependent on devices as ventilators, blood catheters, urinary catheters, $\mathrm{i} / \mathrm{v}$ (intra vascular) catheters etc. ${ }^{1}$ It leads to pneumonia, meningitis, skin infections, urinary tract infections, endophthalmitis and malignant otitis externa. ${ }^{2}$ Different anti-pseudomonal drugs are available but it exhibits multidrug resistance. It has natural aptitude to adopt new ways to resist treatment. So carbapenem is a good choice but many surveillance studies conducted in USA and Europe have shown the increasing prevalence of CRPA (Carbapenem Resistant Pseudomonas Aeruginosa). ${ }^{3,4}$ Beta- lactamase and different genes are responsible for resistance. ${ }^{5,6,7}$ Annually, worldwide antimicrobial resistance was projected to cost over $\$ 105$ billion dollars. ${ }^{8}$ In Pakistan, isolates of Pseudomonas aeruginosa are also detected to have a progressive tendency towards carbapenem resistance. ${ }^{9} \mathrm{WHO}$ publishes an antibiotic resistant list in which P. aeruginosa exhibits carbapenem resisttance is considered as critical pathogens.

\section{METHODOLOGY:}

Google and Google scholar search engine were employed with numerous key words and idioms to search articles related to antibiotic resistance epidemiology in the Gram

M.Phil Student Shaista Bakhat,
Senior Lecturer, Department of Pathology
Bahria University Medical and Dental College
Email: shaistakhurram2@gmail.com
Yasmeen Taj,
Professor, Department of Pathology
Bahria University Medical and Dental College
Faisal Hanif,
Assistant Professor, Department of Pathology
Bahria University Medical and Dental College /
PNS SHIFA Hospital, Karachi
Received: 22-10-18
Accepted: 31-01-19 negative rod shaped bacilli Pseudomonas aeruginosa. Articles were selected from 2013 to 2018 for write up of this review. Key words such as carbapenem resistance, Pseudomonas aeruginosa modified Hodge test and genes detection were used. A total of 200 articles included 5 review articles and 195 original articles. Among 200 articles 40 were short listed on the basis of correlation with my work. A major content of this article is based on genotype detection of antibiotic resistance by Molecular detection of genes that code for enzymes that cause resistance towards traditionally used antibiotics.

\section{LITERATURE REVIEW:}

All over the World carbapenem starts to show its resistance especially hospitalized patients. ${ }^{10}$

Pathogenesis consists of different virulence factors like endotoxin, exotoxin, enzymes, adhesions, biofilms and pigments etc. Endotoxin A is responsible for tissue necrosis, it restrains protein synthesis through ADP-ribosylation of elongation factor-2. Different enzymes eg elastase and proteinases (zinc-metalloprotease and metalloendopeptidases) that make easy incursion into blood-stream. Adhesion through pili can kick off the biofilm formation and phagocytosis. Pigments especially pyocynin can disrupt the movement of cilia and facilitate the secretion accumulation.

LPS (lipopoly-saccharides) are recognasized by TLR4-MD2CD14 which are located on macrophages and dendritic cells, so these take part in inflammation. Flagellum also plays in adhesion, invasion, biofilm formation and mediation of inflammation. Type IV pili binds to glycosphingolipid located on host epithelial cell-membranes.this facilitates the internalization of $P$. aeruginosa. Type IV pili contains pilin protein and indulges in inflammation.

Different drugs are in practice to control pseudomonal drugs eg $\beta$ lactum antibiotics (penicillin, cephalosporine and carbapenem), fluoroquinolone and aminoglycosides. P. aeruginosa is defiant to multiple antibiotics because of unnecessary and inadequate use of these antibiotics. 


\section{CARBAPENEM ANTIMICROBIALS:}

Carbapenems are $\beta$-lactam antibiotics. It binds to pencillinbinding proteins (PBP) and hinder the production of cell wall of micro organism.It is effective against both gram positive and gram negative bacteria ${ }^{11,12}$

Carbapenems were produced from thienamycin that is derivative of streptomyces cattleya. Carbapenems are analogous of pencillin but the sulfur atom in position 1 of the structure has been substituted with a carbon atom. Imipenem is the other antibiotic in this group which was introduced clinically in the United States of America in the year $1985 .{ }^{13}$

Carbapenems cannot move through bacterial cell wall. It pierces through porins. While crossing through the periplasmic space, carbapenems undyingly acylate the PBP (pencilline binding proteins). Carbapenem acts as inhibitors of the enzymes of PBP. At the end cell death of microorganism occurs due to osmotic pressure. ${ }^{14}$

Carbapenems are effective as Empiric monotherapy for ventilator associated pneumonia, intraabdominal infections and infections in cancer patients. ${ }^{15}$ It is contraindicated in those who are hypersensitive because of increased risk of seizure. ${ }^{16}$ Carbapenem can interact with live typhoid vaccine and probenecid. Different mechanisms are involved in carbapenem resistance like:

\section{a. Loss of outer-membrane porins the upregulation of an efflux pump:}

Pseudomonas aeruginosa exhibits resistance to carbapenem due to impermeability through cell-membrane. This impermeability is mediated by MexA-MexB-OprM. Gram negative organism's membrane is naturally designed with pores of Opr-M. MexB protein facilitates the exit portal. This pump comes across impermeability of drugs by upregulation of Mex A-MexB-OprM.This upregulation crop up as a result of nalB mutation.On the other hand Pseudomonas aeruginosa is also set up to lack Opr D proteins. These OprD pores allow the entrance of carbapenems. Whenever these pores are lost, carbapenems have to face the challenges of resistance.

\section{b. Enzymes $\beta$-lactamases}

$\beta$-lactamases are the major reason of microbial resistance to $\beta$-lactam medicine. There are four molecular classes of $\beta$-lactamases A, B, C and D according to Ambler classification. Three classes out of four posses serine amino acid at active site. These classes are A, C and D.

Class A $\beta$-lactamases are the most assorted and widely allocated class of the $\beta$-lactamases. ${ }^{18}$ This class belongs to different enzymes which are chromosomally encoded, for instance NmcA (not metalloenzyme carbapenemases A), SME (Serratia marcescens enzyme), IMI-1 (Imipenemhydrolyzing $\beta$-lactamases), SFC-1(Serratia fonticola carbapenemases-1). But plasmid encoded enzymes are KPC (kleibsiella pneumoniae carbapenemases) and GES (Guiana extended spectrum). Carbapenemases A is monomeric enzyme consisting of 265-269 amino acids. These enzymes inactivate $\beta$-lactams by hydrolysis before it reaches the PBP targets. In serine $\beta$-lactamases hydroxyl group breaks $\beta$ lactam ring. But in case of class $\mathrm{B}$ requires $\mathrm{Zn}^{+2}$ to facilitate the process of hydrolysis. KPC had spread all over the World especially Asia, NorthAmerican, European countries and Africa. ${ }^{19}$

Class B carbapenemases consists of enzymes New Delhi metallo- $\beta$-lactamase 1(NDM-1), Imipenem-resistant pseudomonas (IMP)-type carbapenemases, VIM (Verona integron-encoded metallo- $\beta$-lactamase), GIM (German imipenemase) and SIM (Seoul imipenemase). The NDM7 carbapenemase has been recognized in 2008 in Escherichia coli in France.NDM-1 producing P. aeruginosa isolates are major intimidation to human beings. ${ }^{20}$. These enzymes were detected in pseudomonas, Acinetobacter and Enterobactericeae. ${ }^{21}$

Class D carbapenemases carbapenemases are OXA (Oxacillinase) enzymes. These enzymes are stumbled on P. aeruginosa and Acinetobacter bauminnii. OXA was first discovered in 1985 in Edinburgh, Scotland, by Pton et al. OXA type carbapenemases are majorly discrete in $P$ aeruginosa and $A$. baumannii. Oxacillinase hydrolyses the isoxazolylpencillin oxacillin. Presently 121 variants of class D $\beta$-lactamases have been well-known on the basis of protein and 45 of them reveal carbapenem-hydrolysing activities. ${ }^{22}$

\section{c. Intrinsic resistance}

Pseudomonas aeruginosa acquires high intrinsic resistance. This resistance towards antibiotic inflicts financial burden and patient health. ${ }^{23}$ intrinsic resistance occurs as a result of genes from naturally existing bacteria to clinical pathogen.

\section{THREATS FOR ACQUIREMENT OF CARBAPENEM RESISTANCE}

Resistant isolates of Pseudomonas aeruginosa can cause infections in immune-supressed conditions (neutropenia), elderly patients, hospital acquired infections (mechanical ventilation and organ transplantation), previous exposure to antibiotics, inadequate use of antibiotics and unnecessary use of antibiotics. In order to over-come the problems of antibiotic resistance, nonjudicious use of antibiotics in animals and plants should be avoided. Carbapenem resistance is common in developing countries in sub-saharan Africa. ${ }^{24}$

First report of carbapenem resistance from an aeromonas hydrophila isolate was observed in 1980 in Japan. Consecutively followed in London (1982) from Serratia marcescens (SME-1), IMI-1 from Enterobacter cloacae in Calfornia (1984) and NMC-A from Enterobacter cloacae in France (1990). Carbapenem resistant KPC was firstly recognized in 1996 in United States. Out breaks of KPC 
were existing in Israel, Greece, Colombia, Canada, Australia and New-zealand. ${ }^{25}$ From 2000-2010, infection rates has boosted from $1 \%$ to $12 \%$ in United States. ${ }^{26} \mathrm{KPC}$ gene positive Pseudomonas aeruginosa had found majorly from 2009-2012, $231 \mathrm{KPC}$ - positive strains in 2010, 368 in 2011 and 293 in 2012 were reported ${ }^{27}$ Class D carbapenemases are recently classified under four sub-groups, sub-group-1 is made up of OXA-23, OXA-27 and OXA-49, sub-group2 is composed of OXA-24, OXA-25, OXA-26, OXA-40, sub group 3 is made up of OXA-51 and sub group 4 is made up of OXA-58. In Turkey, carbapenemase resistance is at high rate and resistance is screened for IMP, VIM, OXA23, OXA-27, OXA-49, OXA-25, OXA-26, OXA-40 andOXA-48. The bla OXA-48 gene in pseudomonas aeruginosa isolates were discovered from December 2015 to January 2017 in Khartoum state (Sudan). ${ }^{29}$ OXA-48 producing Klebsiella pneumoniae is recently monitored in France, Belgium, Israel, Russia and the Netherland and exhibit resistance to carbapenem. The bla OXA- 48 gene has been recognized as insertion sequenceIS1999 in Klebsiella pneumonia. The blaoxA-48 was part of transposon (Tn1999) was practical. Now Tn1999 has been discovered in an E. coli in Italy. ${ }^{30}$. But now OXA-48 producing isolates have been documented in Lebanon, Sultanate of Oman, Saudi Arabia and Kwait. Resistance to colistin in Pseudomonas aeruginosa is uncommon but has been occurred. ${ }^{31}$ Resistance to all antibiotics except the polymyxin is now common in numerous hospitals. Daplano et al explained outburst of panresistant Pseudomonas aeruginosa in an intensive care unit in Belgium. In Japan, surveillance for multi-drugresistant Psedomonas aeruginosa described the metallo- $\beta$ lactamase gene blasmp-1 involved in resistance from 2004 to $2006 .{ }^{32}$

\section{PHENOTYPIC AND GENOTYPIC METHODOLOGY}

It can be detected by disc diffusion, MICs, selective agar, modified Hodge test, synergy test, spectrometry, genome sequencing and molecular methods.

\section{Phenotypic detection}

First of all pseudomonas aeruginosa is detected by gram staining from different samples as gram-negative organisms. The organisms can grow on blood agar and MacConkey agar. On blood agar, colonies are grey and irregular as fig no $1 \mathrm{~A}$.

MacConkey is used to differentiate fermenters from non fermenters, as Pseudomonas aeruginosa is non fermenters as per fig 1B. Pseudomonas aeruginosa can also be detected by biochemical test eg oxidase test as per fig 1C. It turns purple within few seconds. For disc diffusion, organism is inoculated on Muller-Hinton Agar. ${ }^{33}$ Then organism is incubated overnight after placing antibiotic discs. Next day inhibitory zone around antibiotic disc is measured according to CLSI. ${ }^{34}$

The modified Hodge Test (MHT) is inexpensive and practicable method. It is used for carbapenemase detection phenotypically and recommened by CLSI. ${ }^{35}$

Break points for carbapenem is revised every year according to CLSI and EUCAST ${ }^{36,37}$ Most Eurpean, Asian and African countries use EUCAST and CLSI as guidelines to detect carbapenemase producing isolates. Whenever these

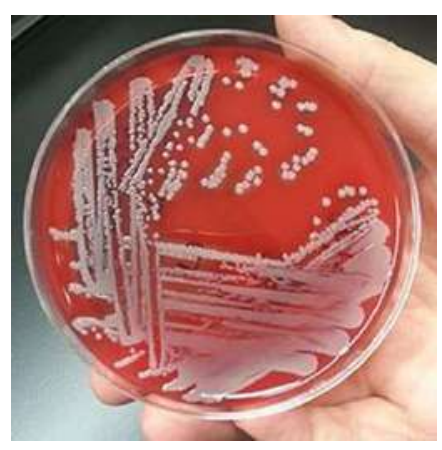

Fig 1A.

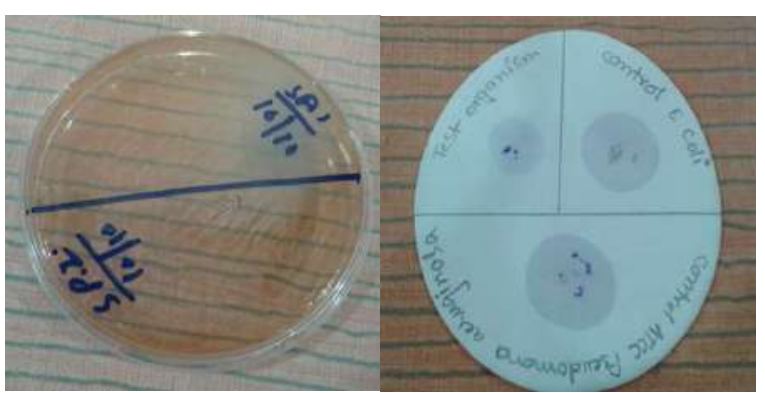

Fig 1B.

\begin{tabular}{|c|c|c|c|c|c|c|c|c|}
\hline \multirow{2}{*}{$\begin{array}{c}\text { Antimicrobial } \\
\text { Agents }\end{array}$} & \multirow{2}{*}{$\begin{array}{c}\text { Disk } \\
\text { content }\end{array}$} & \multicolumn{2}{|c|}{ Zone diameter Break points } & \multicolumn{2}{c|}{ MIC Break points } & \multirow{2}{*}{ Comments } \\
\cline { 3 - 7 } Doripenem & $10 \mu \mathrm{g}$ & $>19 \mathrm{~mm}$ & $16-18 \mathrm{~mm}$ & $<15 \mathrm{~mm}$ & $<2 \mathrm{~mm}$ & $4 \mathrm{~mm}$ & $>8 \mathrm{~mm}$ & $\begin{array}{c}\text { Based on dosage regime } \\
\text { of 500mg every 8hrs }\end{array}$ \\
\hline Imipenem & $10 \mu \mathrm{g}$ & $>19 \mathrm{~mm}$ & $16-18 \mathrm{~mm}$ & $<15 \mathrm{~mm}$ & $<2 \mathrm{~mm}$ & $4 \mathrm{~mm}$ & $>8 \mathrm{~mm}$ & $\begin{array}{c}\text { 1gm for 1hr and } \\
500 \mathrm{mg} \text { every } 6 \mathrm{hrs}\end{array}$ \\
\hline Meropenem & $10 \mu \mathrm{g}$ & $>19 \mathrm{~mm}$ & $16-18 \mathrm{~mm}$ & $<15 \mathrm{~mm}$ & $<2 \mathrm{~mm}$ & $4 \mathrm{~mm}$ & $>8 \mathrm{~mm}$ & 1gm every $8 \mathrm{hrs}$ \\
\hline
\end{tabular}

Zone Break Points And Mic Break Points As Per CLSI

Table 1: As per CLSI 
recommendations are delayed, clinicians and researchers come across problems. Modified Hodge Test is time consuming and unable to detect MBL, but $100 \%$ sensitive for class A and D. ${ }^{38,39}$

\section{Genotype based technique}

Molecular techniques are the most reliable methods for confirmation of carbapenemase production and resistance. Colonies of pseudomonas aeruginosa are detected by polymerase chain reaction within 4-6 hours with specific sensitivity and specificity. Wang et al informed a real time PCR with $100 \%$ sensitivity and specificity. Plasmid located genes like NDM, VIM, IMP and class D serine carbapenemase OXA-48 need to be identified on molecular basis. This procedure will improve the detection of unidentified genes and variants of these genes. A molecular technique consists of different methods like multilocus sequence typing, multilocus enzyme electrophoresis and DNA finger printing methods. OXA-48 is carbapenemhydrolyzing oxacillinase and mostly ubiquitous carbapenemase in Europe and Middle East. Several variants of OXA-48, but most frequent OXA-48 like carbapenemases, have been documented which change from OXA-48 on basis of amino acids e.g, OXA-162, OXA-163, OXA-181 and OXA- $204 .^{40}$

It is confirmatory test for detection of carbapenem resistance. It is fast and reliable methods helping diagnosis and treatment. ${ }^{41}$ Molecular methods can detect and differentiate carbapenemase consisting of NDM, KPC and OXA-48 mediated resistance, which is significant for epidemiological investigations. ${ }^{42}$

\section{TREATMENT ALTERNATIVES IN CARBAPENEM RESISTANT PSEUDOMONAS AERUGINOSA}

Pseudomonas aeruginosa is majorly involved in serious hospital-acquired infections. It builds up Sresistance to multiple antibiotics. Colistin is used as salvage therapy of Pseudomonas aeruginosa infections when resistance is common towards carbapenems. This drug reveals $98.8 \%$ susceptibility according to the U.S survey. According to retrospective cohort study, colistin was used in 23 seriously ill patients with multiple -drug resistance Pseudomonas aeruginosa infections; response was $61 \%$ with 3 patients showed resistance. Ceftolozane-tazobactam indicates excellent afficacy against many multi-drug resistant isolates. $\mathrm{C} / \mathrm{T}$ was active against 95.2\% CRPA (Carbapenem resistant Pseudomonas aeruginosa) clinical isolates. C/A (ceftazidimeavibactam) and $\mathrm{C} / \mathrm{T}$ (ceftolozane-Tazobactam) are effective in case of over expression of oprD, efflux pumps and chromosomal ampC among non carbapenemase-producing CRPA clinical isolates. ${ }^{43}$ Thirty seven patients were treated for bacteremia with carbapenem resistant (CR) pseudomonas aeruginosa. Among these patients, $65 \%$ of isolates exhibited multi-drug resistance. ${ }^{44}$

\section{MEASURES REQUIRED TO OVERCOME CARBAPENEM RESISTANCE}

Resistance towards carbapenem is identified as one of the greatest threats to human health over the World. Almost 2 million Americans per year suffer from nosocomial infections, leading to 99,000 deaths as a result of antibiotic resistance. Coordinated intrusion should be designed to get better use of antibiotics. Unecessary and inappropriate antibiotics should be avoided. We should discontinue the use of antibiotics for rapid growth and prevention of diseases in animals as well as in crops. The intimidation must be controlled by strict infection control policies and guidelines planned for every country. Skillful identification of carbapenemase productions by microbiology laboratories plays a vital role in infection control. ${ }^{45}$ Therapy of resistant pathogen should be selected with regarding pharmacokinetics and pharmacodynamics. ${ }^{46}$ Pseudomonas aeruginosa resistant genes have been detected globally, especially in Europe, South Asia and America. Hence there is an urgent need for infection control stewardship policy to control dissemination of resistance.

\section{CONCLUSION:}

Pseudomonas aeruginosa has the capacity of transferring antibiotic resistant genes to susceptible population of microorganisms.

\section{REFERENCES:}

1. G Meletis, M Exindari, N Vavatsi, D Sofianou, E Diza "Mechanisms responsible for the emergence of carbapenem resistance in pseudomobnas aeruginosa" Hippokrati 2012; 16(4):303-307.

2. Golle A, Janezic S, Rupnik M. Low overlap between carbapenem resistant Pseudomonas aeruginosa genotypes isolated from hospitalized patients and wastewater treatment plants. PloS one.2017; 12(10):e0186736.

3. Lin KY, Lauderdale TL, Wang JT, Chang SC. Carbapenemresistant Pseudomonas aeruginosa in Taiwan: Prevalence, risk factors, and impact on outcome of infections. JMI 2016; 49(1):52-9.

4. Zhang Y, Chen XL, Huang AW, Liu SL, Liu WJ, Zhang N, Lu XZ. Mortality attributable to carbapenem-resistant Pseudomonas aeruginosa bacteremia: a meta-analysis of cohort studies. ;jEMI 2016; 5(3):e27.

5. Gonçalves IR, Dantas RC, Ferreira ML, Batistão DW, GontijoFilho PP, Ribas RM. Carbapenem-resistant Pseudomonas aeruginosa: association with virulence genes and biofilm formation. Braz J Microbiol 2017; 48(2):211-7.

6. Al-Agamy MH, Jeannot K, El-Mahdy TS, Samaha HA, Shibl AM, Plésiat P, Courvalin P. Diversity of molecular mechanisms conferring carbapenem resistance to Pseudomonas aeruginosa isolates from Saudi Arabia, can J infect Dis Med Microbiol. 2016

7. Dantas RC, Ferreira ML, Gontijo-Filho PP, Ribas RM. Pseudomonas aeruginosa bacteraemia: sindependent risk factors for mortality and impact of resistance on outcome. jm 2014; 63 (12):1679-87. 
8. Codjoe FS, Donkor ES. Carbapenem resistance: a review. Med Sci, 2017; 6(1):1.

9. Khan F, Khan A, Kazmi SU. Prevalence and susceptibility pattern of multi drug resistant clinical isolates of Pseudomonas aeruginosa in Karachi. Pak J Med Sci. 2014 Sep; 30 (5):951.

10. Buehrle DJ, Shields RK, Clarke LG, Potoski BA, Clancy CJ, Nguyen MH. Carbapenem-resistant Psesudomonas aeruginosa bacteremia: risk factors for mortality and microbiologic treatment failure. Antimicrob agents chemoth. 2017; 61(1):e01243-16.

11. El-Gamal MI, Brahim I, Hisham N, Aladdin R, Mohammed $\mathrm{H}$, Bahaaeldin A. Recent updates of carbapenem antibiotics. Eur J Med Chem. 2017; 131:185-95.

12. Zeng $\mathrm{X}$, Lin J. Beta-lactamase induction and cell wall metabolism in Gram-negative bacteria. jFM 2013; 22(4):128.

13. Jeon JH, Lee JH, Lee JJ, Park KS, Karim AM, Lee CR, Jeong BC, Lee SH. Structural basis for carbapenem-hydrolyzing mechanisms of carbapenemases conferring antibiotic resistance. ijms, 2015; 16(5):9654-92.

14. Chow DC, Rice K, Huang W, Atmar RL, Palzkill T. Engineering specificity from broad to narrow: design of a $\beta$ lactamase inhibitory protein (BLIP) variant that exclusively binds and detects KPC $\beta$-lactamase. acs, 2016; 2(12):969-79.

15. Kripalani S, Jackson AT, Schnipper JL, Coleman EA. Promoting effective transitions of care at hospital discharge: a review of key issues. for hospitalists. Journal of hospital medicine: an official publication of the Society of Hospital Medicine. 2007 ;2(5):314-23

16. Huprikar S, Casner L, Pouch S, Pinheiro Freire M, Madan R, Kwak E, Satlin M, Hartman P, Pisney L, Henrique Mourao P, La Hoz R. Prior Infection or Colonization with CarbapenemResistant Enterobacteriaceae Is Not an Absolute Contraindication for Solid Organ Transplantation. In american journal of transplantation. American J Ther. 2016;(16)260.

17. Dantas RC, e Silva RT, Ferreira ML, Gonçalves IR, Araújo BF, de Campos PA, Royer S, da Fonseca Batistão DW, GontijoFilho PP, Ribas RM. Molecular epidemiological survey of bacteremia by multidrug resistant Pseudomonas aeruginosa: the relevance of intrinsic resistance mechanisms. PloS one. 2017; 12(5):e0176774.

18. Bakthavatchalam YD, Anandan S, Veeraraghavan B. Laboratory detection and clinical implication of oxacillinase48 like carbapenemase: the hidden threat. J Glob Infect Dis, 2016; 8(1):41.

19. Nakano R, Nakano A, Ishii Y, Ubagai T, Kikuchi-Ueda T, Kikuchi H, Tansho-Nagakawa S, Kamoshida G, Mu X, Ono Y. Rapid detection of the Klebsiella pneumoniae carbapenemase (KPC) gene by loop-mediated isothermal amplification (LAMP). J Intensive Care Med 2015; 21(3):2026.

20. Wailan AM, Paterson DL. The spread and acquisition of NDM-1: a multifactorial problem. Expert Rev of Anti-infect ther. $2014 ; 12(1): 91-115$.

21. Labarca JA, Salles MJ, Seas C, Guzmán-Blanco M. Carbapenem resistance in Pseudomonas aeruginosa and Acinetobacter baumannii in the nosocomial setting in Latin America. Crit Rev Microbiol. 2016; 42(2):276-92.

22. Ma L, Wang JT, Wu TL, Siu LK, Chuang YC, Lin JC, Lu MC, Lu PL. Emergence of OXA-48-producing Klebsiella pneumoniae in Taiwan. PLoS One. 2015; 10(9):e0139152.
23. Murray JL, Kwon T, Marcotte EM, Whiteley M. Intrinsic antimicrobial resistance determinants in the superbug Pseudomonas aeruginosa. MBio. 2015; 6(6):e01603-15.

24. Donkor ES, Newman MJ, Tay SC, Dayie NT, Bannerman E, Olu-Taiwo M. Investigation into the risk of exposure to antibiotic residues contaminating meat and egg in Ghana. Food Control. 2011;22(6):869-73.

25. Shallcross LJ, Howard SJ, Fowler T, Davies SC. Tackling the threat of antimicrobial resistance: from policy to sustainable action. Philos Trans R Soc Lon Biol Sci 2015; 370(1670) :20140082

26. Kuehn BM. "Nightmare" bacteria on the rise in US hospitals, long-term care facilities. Jama. 2013;309(15):1573-4.

27. Karkey A, Thanh DP, Boinett CJ, Cain AK, Ellington M, Baker KS, Dongol S, Thompson C, Harris SR, Jombart T, Phuong TL. A high-resolution genomic analysis of multidrugresistant hospital outbreaks of Klebsiella pneumoniae. EMBO molecular medicine 2015; 7(3):227-39.

28. Carrër A, Poirel L, Eraksoy H, Cagatay AA, Badur S, Nordmann P. Spread of OXA-48-positive carbapenem-resistant Klebsiella pneumoniae isolates in Istanbul, Turkey. Antimicrob agents chemother. $2008 ; 52(8): 2950-4$.

29. Elnour S, Alobied A, Hussain W and Ibrahim M "The blaOXA48 carbapenem resistant Pseudomoas aeruginosa clinical isolates in Sudan" J Advances in Microbiology 2018; 10(4):15;2456-711629.

30. Giani T, Conte V, Di Pilato V, Aschbacher R, Weber C, Larcher C, Rossolini GM. Escherichia coli from Italy producing OXA48 carbapenemase encoded by a novel Tn1999 transposon derivative.J Antimicrob chemother. 2012; 56(4):2211-3.

31. Almasaudi SB. Acinetobacter spp. as nosocomial pathogens: Epidemiology and resistance features. Saudi J Biol Sci, 2018; 25(3):586-96.

32. Klockgether J, Tümmler B. Recent advances in understanding Pseudomonas aeruginosa as a pathogen. F1000Res 2017; 6:1261.

33. Van Dijk K, Voets GM, Scharringa J, Voskuil S, Fluit AC, Rottier WC, Leverstein-Van Hall MA, Stuart JC. A disc diffusion assay for detection of class A, B and OXA-48 carbapenemases in Enterobacteriaceae using phenyl boronic acid, dipicolinic acid and temocillin. JCMI 2014;20(4):345-9.

34. Xie J, Yang L, Peters BM, Chen L, Chen D, Li B, Li L, Yu G, Xu Z, Shirtliff ME. A 16-year retrospective surveillance report on the pathogenic features and antimicrobial susceptibility of Pseudomonas aeruginosa isolates from FAHJU in Guangzhou representative of Southern China. Microb pathog. 2017; 110:37-41.

35. Piedra-Carrasco N, Fàbrega A, Calero-Cáceres W, CornejoSánchez T, Brown-Jaque M, Mir-Cros A, Muniesa M, González-López JJ. Carbapenemase-producing enterobacteriaceae recovered from a Spanish river ecosystem. PloS one. 2017; 12(4):e0175246.

36. Sachdeva R, Sharma B, Sharma R. Evaluation of different phenotypic tests for detection of metallo- $\beta$-lactamases in imipenem-resistant Pseudomonas aeruginosa. J lab physicians. 2017; 9(4):249.

37. Lutgring JD, Limbago BM. The problem of carbapenemase producing carbapenem-resistant Enterobacteriaceae detection. JCM 2016;-02771. 
38. Gupta V, Garg R, Kumaraswamy K, Datta P, Mohi GK, Chander J. Phenotypic and genotypic characterization of carbapenem resistance mechanisms in Klebsiella pneumoniae from blood culture specimens: A study from North India. J Lab Phonol $2018 ; 10(2): 125$.

39. Pragasam AK, Veeraraghavan B, Bakthavatchalam YD, Gopi $\mathrm{R}$, Aslam RF. Strengths and limitations of various screening methods for carbapenem-resistant Enterobacteriaceae including new method recommended by clinical and laboratory standards institute, 2017: A tertiary care experience. Iran J Microbiol 2017; 35(1): 116 .

40. Song W, Hong SG, Yong D, Jeong SH, Kim HS, Kim HS, Kim JS, Bae IK. Combined use of the modified hodge test and carbapenemase inhibition test for detection of carbapenemase-producing Enterobacteriaceae and metallo$\beta$-lactamase-producing Pseudomonas spp. Sci public policy 2015; 35(2):212-9.

41. Laolerd W, Akeda Y, Preeyanon L, Ratthawongjirakul P, Santanirand P. Carbapenemase-Producing CarbapenemResistant Enterobacteriaceae from Bangkok, Thailand, and Their Detection by the Carba NP and Modified Carbapenem Inactivation Method Tests. Microb Drug Resist 2018; 24(7): 1006-1011.
42. Blair JM, Webber MA, Baylay AJ, Ogbolu DO, Piddock LJ. Molecular mechanisms of antibiotic resistance. Nat Rev Microbiol. 2015; 13(1):42.

43. Bialvaei AZ, Kafil HS, Asgharzadeh M, Yousef Memar M, Yousefi M. Current methods for the identification of carbapenemases. J Chemother 2016 ;28(1):1-9.

44. Bedeniæ B, Pleèko V, Sardeliæ S, Uzunoviæ S, Godiè Torkar $\mathrm{K}$. Carbapenemases in gram-negative bacteria: laboratory detection and clinical significance. BioMed res Int 2014; 2014 : 841951.

45. Mensa J, Barberán J, Soriano A, Llinares P, Marco F, Cantón R, Bou G, del Castillo JG, Maseda E, Ramón Azanza J, Pasquau J. Antibiotic selection in the treatment of acute invasive infections by Pseudomonas aeruginosa: Guidelines by the Spanish Society of Chemotherapy. Rev Esp Quimioter. 2018; 31(1).

46. Fritzenwanker M, Imirzalioglu C, Herold S, Wagenlehner FM, Zimmer KP, Chakraborty T. Treatment options for carbapenem-Resistant Gram negative infections: Dt Sch Arztebl Int 2018;115(20-21): 345-352. 